\title{
Proinflammatory cytokines and matrix metalloproteinases in CSF of patients with VZV vasculopathy \\ OPEN
}

Dallas Jones, $\mathrm{PhD}$

Enrique Alvarez, MD,

$\mathrm{PhD}$

Sean Selva, BS

Don Gilden, MD

Maria A. Nagel, MD

Correspondence to

Dr. Nagel:

maria.nagel@ucdenver.edu

\section{ABSTRACT}

Objective: To determine the levels of proinflammatory cytokines and matrix metalloproteinases (MMPs) in the CSF of patients with virologically verified varicella zoster virus (VZV) vasculopathy.

Methods: CSF from 30 patients with virologically verified VZV vasculopathy was analyzed for levels of proinflammatory cytokines and MMPs using the Meso Scale Discovery multiplex ELISA platform. Positive CNS inflammatory disease controls were provided by CSF from 30 patients with multiple sclerosis. Negative controls were provided by CSF from 20 healthy controls.

Results: Compared to multiple sclerosis CSF and CSF from healthy controls, levels of interleukin (IL)-8, IL-6, and MMP-2 were significantly elevated in VZV vasculopathy CSF.

Conclusions: CSF of patients with VZV vasculopathy revealed a unique profile of elevated proinflammatory cytokines, IL-8 and IL-6, along with elevated MMP-2. The relevance of these cytokines to the pathogenesis of VZV vasculopathy requires further study. Neurol Neuroimmunol Neuroinflamm 2016;3:e246; doi: 10.1212/NXI.0000000000000246

\section{GLOSSARY}

GCA = giant cell arteritis; IFN = interferon; IL = interleukin; MMP = matrix metalloproteinase; $\mathbf{M S}=$ multiple sclerosis; TNF- $\boldsymbol{\alpha}=$ tumor necrosis factor $\alpha ; \mathbf{V Z V}=$ varicella zoster virus.

Varicella zoster virus (VZV) is a neurotropic DNA alphaherpesvirus that infects $>95 \%$ of humans worldwide. Primary infection causes varicella (chickenpox) after which VZV becomes latent in cranial nerve ganglia, dorsal root ganglia, and autonomic ganglia along the entire neuraxis. As VZV-specific cell-mediated immunity declines in elderly or immunosuppressed individuals, VZV reactivates to cause zoster (shingles). Zoster may be further complicated by infection of cerebral arteries, resulting in pathologic vascular remodeling and stroke (VZV vasculopathy). VZV vasculopathy is associated with a thickened intima composed of myofibroblasts, a paucity of smooth muscle cells in media, and disruption of the internal elastic lamina. ${ }^{1}$ Key mediators in vascular remodeling associated with VZV vasculopathy are proinflammatory cytokines that promote cell migration, proliferation and tissue damage, as well as matrix metalloproteinases (MMPs) that degrade extracellular matrix to promote tissue remodeling and infiltration of immune cells. ${ }^{2}$ Thus, we examined levels of proinflammatory cytokines and MMPs in the CSF of patients with virologically confirmed VZV vasculopathy.

METHODS Standard protocol approvals, registrations, and patient consents. Deidentified CSF from patients with multiple sclerosis (MS) and healthy controls was provided by the Rocky Mountain Multiple Sclerosis Center Biorepository, whose collection protocol for CSF was approved by the Colorado Multiple Institutional Review Board (12-0968).

Deidentified, archived CSF from patients with VZV vasculopathy was obtained from the laboratory of Don Gilden, which receives multiple specimens to confirm or repudiate the diagnosis of VZV vasculopathy.

Cerebrospinal fluid. Three groups of deidentified CSF were obtained according to Colorado institutional review board guidelines. The first group was CSF from 30 patients with virologically verified VZV vasculopathy, ${ }^{3}$ defined as patients who presented with TIAs or

From the Departments of Neurology (D.J., E.A., S.S., D.G., M.A.N.) and Immunology and Microbiology (D.G.), University of Colorado School of Medicine, Aurora.

Funding information and disclosures are provided at the end of the article. Go to Neurology.org/nn for full disclosure forms. The Article Processing Charge was paid by the authors.

This is an open access article distributed under the terms of the Creative Commons Attribution-NonCommercial-NoDerivatives License 4.0 (CC BY-NC-ND), which permits downloading and sharing the work provided it is properly cited. The work cannot be changed in any way or used commercially. 
stroke and whose CSF contained anti-VZV immunoglobulin G antibodies by ELISA ( $50 \%$ women, average age 56.7 years, range $20-75$ years). The second group was CSF from 30 positive control CNS inflammatory disease patients with MS, including 17 with relapsing-remitting MS, 2 of whom were taking interferon (IFN) beta-1a or corticosteroids, and 13 patients with primary progressive MS (70\% women, average age 44.3 years, range $24-62$ years). The third group (negative control) was CSF from 20 healthy patients with no history of neurologic disease $(90 \%$ women, average age 36.6 years, range $18-65$ years). All CSF samples were centrifuged within 30 minutes at $800 \mathrm{rpm}$ at $4^{\circ} \mathrm{C}$ for 5 minutes, and the supernatant was stored at $-80^{\circ} \mathrm{C}$ until use.

Multiplex electrochemiluminescence immunoassay. Levels of 10 cytokines in the liquid phase of the CSF, including IL-1 $\beta$, IL-2, IL-4, IL-6, IL-8, IL-10, IL-12p70, IL-13, IFN gamma (IFN $\gamma$ ), and tumor necrosis factor $\alpha$ (TNF- $\alpha$ ), were measured using the Meso Scale Discovery Proinflammatory Panel 1 kit (Rockville, MD) according to the manufacturer's instructions. Levels of 5 MMPs in the liquid phase of CSF, i.e., MMP-1, -2, $-3,-9$, and -10 , were measured using Meso Scale Discovery's MMP 2-Plex and MMP 3-Plex Ultra-Sensitive kits (Rockville, $\mathrm{MD}$ ) according to the manufacturer's instructions. Cytokine and MMP concentrations were calculated by reference to a standard curve for each molecule derived using various concentrations of the standards assayed in the same manner as the CSF samples. The lower and upper limits of detection were calculated based on the concentration of signal equal to $2.5 \mathrm{SDs}$ above the zero calibrator and below the upper plateau of the standards curve, respectively. All samples were analyzed in duplicate.

Statistical analysis. Kruskal-Wallis analysis was used to compare differences among the 3 groups and between individual groups.
RESULTS Cytokine levels in VZV vasculopathy CSF. Significantly increased levels of IL-8 $(p<0.0001)$, IL-6 $(p=0.007)$, and IL-12p70 $(p=0.011)$ were found in VZV vasculopathy CSF compared to those in MS CSF, as well as significantly increased levels of IL-8 $(p<0.0001)$, IL-6 $(p=0.0001)$, IFN $\gamma$ $(p=0.0004)$, TNF- $\alpha(p=0.0012)$, IL-1 $\beta(p=$ $0.006)$, and IL-2 $(p=0.01)$ in VZV vasculopathy CSF compared to healthy control patient CSF. Levels of IL-8 $(p<0.004)$, IL-6 $(p=0.002)$, IFN $\gamma(p<$ $0.0001)$, TNF- $\alpha(p<0.0001)$, IL-1 $\beta(p<0.0001)$, IL-2 $(p<0.0001)$, and IL-10 $(p<0.0001)$ were also significantly increased in MS CSF as compared to those in healthy control patient CSF (table, figure 1).

MMP levels in VZV vasculopathy CSF. CSF MMP-2 levels were significantly increased in patients with VZV vasculopathy compared to those in MS CSF $(p=0.0001)$, and significantly higher levels of MMP-1 $(p=0.0002)$, MMP-2 $(p=0.0001)$, MMP-3 $(p=0.0002)$, MMP-9 $(p<0.0001)$, and MMP-10 $(p<0.0001)$ were detected in VZV vasculopathy CSF compared to those in healthy control patient CSF; MMP-1 $(p=0.0009)$, MMP-2 $(p=0.0001)$, MMP-3 $(p<0.0001)$, MMP-9 $(p<0.0001)$, and MMP-10 $(p<$ $0.0001)$ levels were significantly higher in CSF from patients with MS than those in controls (table, figure 2).

\begin{tabular}{|c|c|c|c|c|c|}
\hline $\begin{array}{l}\text { Meso } \\
\text { and } f t\end{array}$ & $\begin{array}{l}\text { Discovery analyt } \\
\text { ealthy controls }\end{array}$ & Is in CSF from $p$ & with VZV vasc & hy, patien & MS, \\
\hline \multirow[b]{2}{*}{ Analytes } & \multicolumn{3}{|l|}{ Groups, median (range) } & \multirow[b]{2}{*}{ LLOD-ULOD } & \multirow[b]{2}{*}{$p$ Value } \\
\hline & VZV vasculopathy & MS & Control & & \\
\hline IL-8, pg/mL & $72.0(21.2-1308)$ & $28.0(10.5-66.2)$ & $21.8(12.7-54.8)$ & $0.100-516$ & 0.0001 \\
\hline IL-6, pg/mL & $1.52(0.13-70.7)$ & $0.67(0.29-2.08)$ & $0.424(0.15-1.0)$ & $0.130-657$ & 0.0001 \\
\hline $\mathrm{IL}-1 \beta, \mathrm{pg} / \mathrm{mL}$ & $0.038(0.0-1.14)$ & $0.05(0.0-0.26)$ & $0.0(0.0-0.13)$ & $0.040-630$ & 0.0005 \\
\hline TNF- $\alpha, p g / m L$ & $0.156(0.0-11.0)$ & $0.163(0.0-0.35)$ & $0.065(0.0-0.097)$ & $0.09-311$ & 0.0001 \\
\hline $\mathrm{IFN} \gamma, \mathrm{pg} / \mathrm{mL}$ & 0.64 (0.0-704) & $0.875(0.0-5.5)$ & $0.05(0.0-0.7)$ & $0.45-1320$ & 0.0001 \\
\hline $\mathrm{IL-2}, \mathrm{pg} / \mathrm{mL}$ & $0.263(0.02-1.26)$ & $0.329(0.07-0.63)$ & $0.124(0.01-0.27)$ & $0.08-1330$ & 0.0001 \\
\hline IL-10, pg/mL & $0.056(0.0-5.40)$ & $0.097(0.0-0.66)$ & $0.035(0.0-0.10)$ & $0.04-323$ & 0.0007 \\
\hline IL-4, pg/mL & $0.016(0.0-0.14)$ & $0.009(0.0-0.05)$ & $0.016(0.0-0.06)$ & $0.03-191$ & 0.1448 \\
\hline IL-12p70, pg/mL & $0.043(0.0-0.92)$ & $0.017(0.0-0.11)$ & $0.037(0.0-0.18)$ & $0.10-416$ & 0.0240 \\
\hline IL-13, pg/mL & $0.122(0.0-3.3)$ & $0.102(0.0-1.0)$ & $0.0(0.0-0.54)$ & $0.82-495$ & 0.1400 \\
\hline MMP-1, ng/mL & $0.023(0.004-0.888)$ & $0.017(0.003-0.056)$ & $0.009(0.001-23.0)$ & $0.0018-100$ & 0.0002 \\
\hline MMP-2, ng/mL & 35.3 (7.9-102.8) & 21.4 (14.5-31.9) & 13.9 (7.9-26.3) & $0.0919-500$ & 0.0001 \\
\hline MMP-3, ng/mL & $0.168(0.02-2.69)$ & $0.190(0.07-0.755)$ & $0.060(0.027-0.304)$ & $0.0007-100$ & 0.0001 \\
\hline MMP-9, ng/mL & $0.315(0.069-23.65)$ & $0.477(0.08-6.12)$ & $0.045(0.013-0.098)$ & $0.0137-500$ & 0.0001 \\
\hline MMP-10, ng/mL & $0.053(0.01-0.359)$ & $0.060(0.035-0.162)$ & $0.018(0.012-0.043)$ & $0.0051-100$ & 0.0001 \\
\hline
\end{tabular}

Abbreviations: IFN $\gamma=$ interferon gamma; IL = interleukin; LLOD-ULOD = lower limits of detection-upper limits of detection; MMP = matrix metalloproteinase; MS = multiple sclerosis; TNF- $\alpha=$ tumor necrosis factor $\alpha$; VZV = varicella zoster virus. 
A. IL-8*

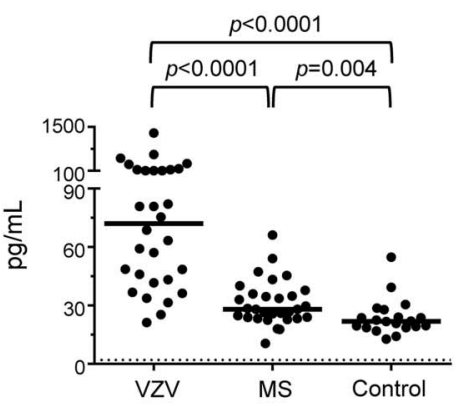

E. IL-1 $\beta^{*}$

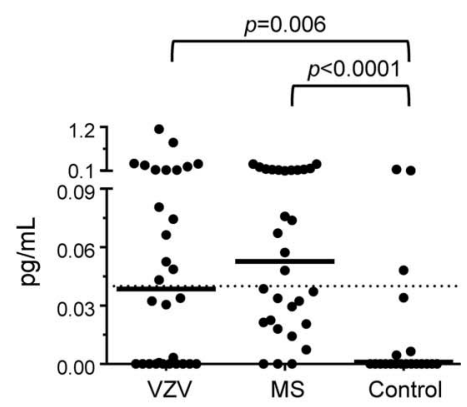

I. IL-4

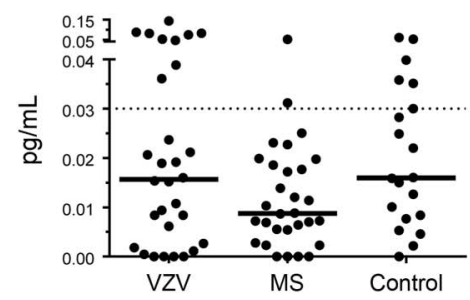

B. IL-6*

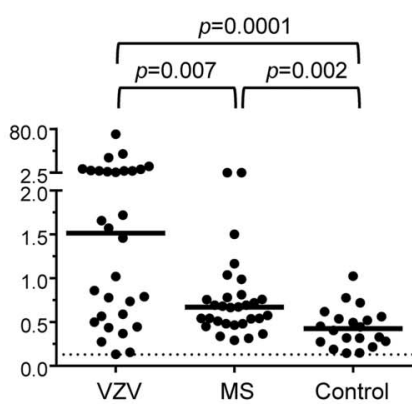

F. IL-2*
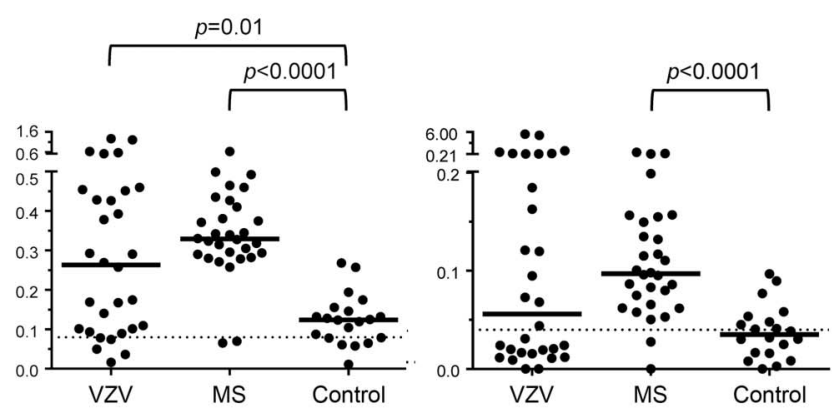

G. IL-10*

D. TNF $\alpha^{*}$

C. IFN $\gamma^{*}$
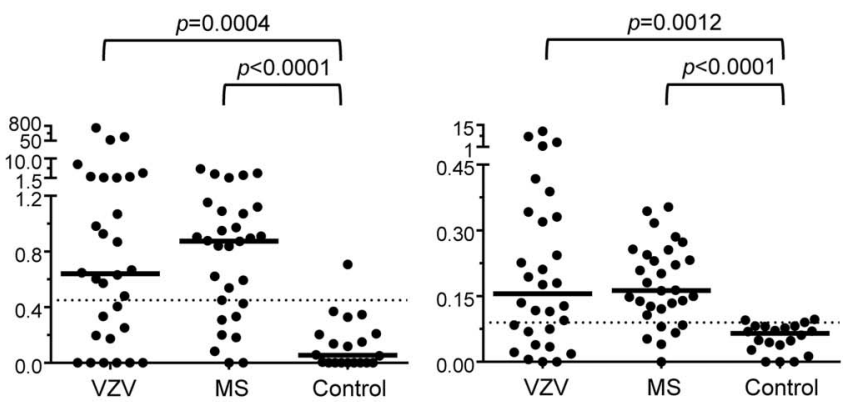

H. IL-12p70*

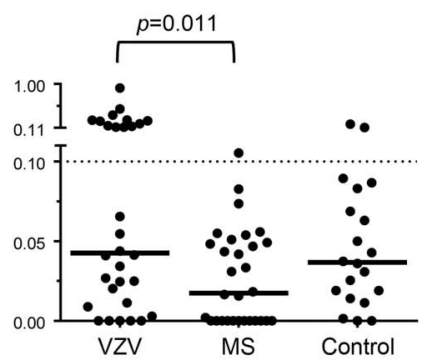

Levels of IL-8 $(p<0.0001)$, IL-6 ( $p=0.007)$ and $(H)$ IL-12p70 ( $p=0.011)$ were significantly higher in VZV vasculopathy CSF than those in MS CSF. Compared to CSF from healthy controls, (A) IL-8 $(p<0.0001)$, (B) IL-6 $(p=0.0001)$, (C) IFN $\gamma(p=0.0004)$, (D) TNF- $\alpha(p=0.0012)$, (E) IL-1 $\beta(p=0.006)$, and (F) IL-2 ( $p=0.01)$ levels were significantly higher in VZV vasculopathy CSF, and levels of IL-8 $(p<0.004)$, IL-6 $(p=0.002)$, IFN $\gamma(p<0.0001)$, TNF- $\alpha(p<$ 0.0001), IL-1 $(p<0.0001)$, IL-2 ( $<$ 0.0001), and (G) IL-10 ( $<0.0001)$ were significantly higher in MS CSF. (I) IL-4 and (J) IL-13 levels did not differ significantly among the 3 groups. Each dot represents cytokine values for individual patients; solid bars represent median CSF cytokine levels for each group. Dotted lines represent lower limits of detection for each cytokine. The asterisk represents statistically significant differences in median cytokine levels among the 3 groups. IFN $\gamma=$ interferon gamma; IL = interleukin; MS = multiple sclerosis; TNF- $\alpha=$ tumor necrosis factor $\alpha$; VZV $=$ varicella zoster virus.

DISCUSSION Because vascular remodeling is caused, in part, by inflammation and degradation of the extracellular matrix, we analyzed the levels of proinflammatory cytokines and MMPs in CSF from patients with VZV vasculopathy compared to inflammatory CSF from patients with MS and CSF from healthy controls. Elevated levels of IL-8, IL-6, IL-1 $\beta$, TNF- $\alpha$, IFN $\gamma$, and IL-2, as well as MMP-1, -2, -3, -9 and -10, in patients with VZV vasculopathy and patients with MS are consistent with the inflammatory nature of both disorders.

The specific elevation of IL-8 in VZV vasculopathy CSF compared to MS CSF and CSF from healthy controls is important because it is a proinflammatory cytokine/chemokine that recruits neutrophils, consistent with an abundance of neutrophils in cerebral arteries in early VZV vasculopathy, ${ }^{2}$ in zoster vesicular fluid, ${ }^{4}$ and in the CSF of patients with VZV inflammatory brainstem disease. ${ }^{5}$

The significant elevation of IL-6 in VZV vasculopathy CSF compared to CSF of both patients with MS and healthy controls likely reflects its proinflammatory role in inducing differentiation of macrophages, ${ }^{6}$ which are prominent in VZV-infected cerebral arteries of patients with VZV vasculopathy. ${ }^{2}$ IL-6 also induces smooth muscle cell migration and proliferation, ${ }^{7}$ which contribute to myofibroblast accumulation in the thickened intima of VZV-infected cerebral arteries. ${ }^{1}$ Increased levels of IL-12p70 in some VZV vasculopathy CSF compared to MS CSF likely mirrors T cell activation and secretion of inflammatory cytokines, consistent with the prevalence of T cells in VZV-infected arteries. ${ }^{2}$ 
Figure 2 MMP levels in CSF from patients with VZV vasculopathy, patients with MS, and from healthy controls

A. MMP-1*

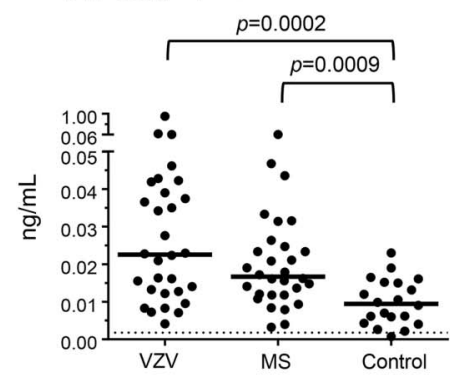

B. MMP-2*

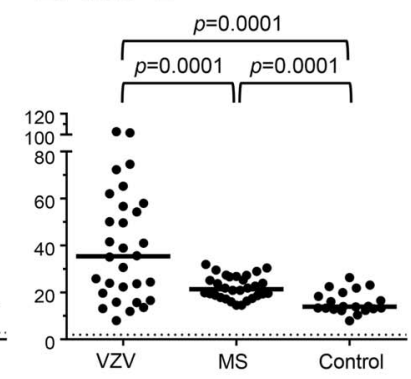

C. MMP-3*

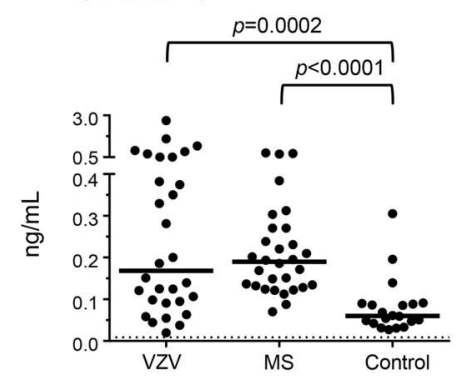

D. MMP-9*

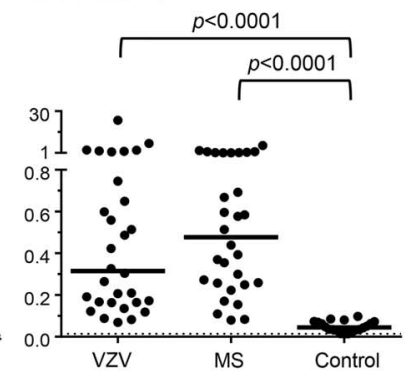

E. MMP-10*

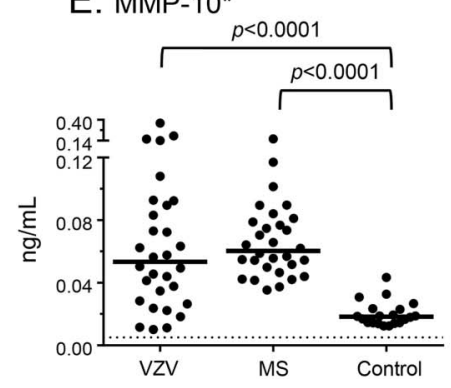

MMP-2 levels were significantly higher in VZV vasculopathy CSF than those in MS CSF ( $p=$ 0.0001). Compared to CSF from healthy controls, levels of (A) MMP-1 ( $p=0.0002)$, (B) MMP-2 ( $p=0.0001),(C)$ MMP-3 ( $=0.0002)$, (D) MMP-9 ( $<0.0001)$, and (E) MMP-10 $(p<0.0001)$ were significantly higher in VZV vasculopathy, and levels of MMP-1 ( $p=$ 0.0009), MMP-2 ( $p=0.0001)$, MMP-3 ( $<0.0001)$, MMP-9 $(p<0.0001)$, and MMP-10 $(p<0.0001)$ were significantly increased in CSF from patients with MS. Each dot represents MMP values from an individual patient, and solid bars represent median CSF MMP levels for each group. Dotted lines represent lower limits of detection for each MMP. The asterisk represents statistically significant differences in median MMP levels among the 3 groups. $\mathrm{MMP}=$ matrix metalloproteinase; $\mathrm{MS}=$ multiple sclerosis; VZV = varicella zoster virus.

Unlike VZV vasculopathy CSF, that of patients with MS showed elevated IL-10 levels, consistent with an earlier report ${ }^{8}$ and with the role of IL-10 in promoting antibody production in this $\mathrm{B}$ cell-driven disease.

The significant elevation of MMP-2 in VZV vasculopathy CSF compared to MS CSF and CSF of healthy controls most likely reflects increased degradation of the extracellular matrix in VZV-infected arteries. Our findings of elevated MMPs in VZV vasculopathy and MS CSF support the role of multiple classes of MMPs in degradation of the extracellular matrix, tissue remodeling, and angiogenesis associated with inflammatory CNS diseases.
Finally, the pathology of both intracerebral VZV vasculopathy and giant cell arteritis (GCA) is identical and characterized by granulomatous arteritis. Furthermore, VZV antigen is present in both cerebral arteries of patients with VZV vasculopathy and in the temporal arteries of patients with GCA. ${ }^{9}$ Thus, GCA is likely to be an extracranial form of VZV vasculopathy in which the temporal artery is primarily affected. Consistent with this notion are the significantly increased levels of IL-8, IL-6, and MMP-2 in VZV vasculopathy CSF compared to MS CSF and control CSF, which parallel elevated levels of (1) IL-8 and neutrophils in the blood of patients with GCA during corticosteroid taper, ${ }^{10}(2)$ IL-6 in the serum of patients with GCA, ${ }^{11}$ and (3) MMP-2 in temporal artery biopsies and in the aorta of patients with GCA. ${ }^{12}$

\section{AUTHOR CONTRIBUTIONS}

Dr. Jones: drafted and revised the manuscript for content, collected, analyzed, and interpreted data. Dr. Alvarez: provided samples, analyzed and interpreted data. Mr. Selva: provided samples, analyzed and interpreted data. Dr. Gilden: drafted and revised the manuscript for content, designed and supervised the study, collected, analyzed, and interpreted data. Dr. Nagel: drafted and revised the manuscript for content, designed and supervised the study, collected, analyzed, and interpreted data.

\section{ACKNOWLEDGMENT}

The authors thank Marina Hoffman for editorial review and Cathy Allen for word processing and formatting, and the Rocky Mountain Multiple Sclerosis Center Biorepository at the University of Colorado for providing CSF samples.

\section{STUDY FUNDING}

This work was supported in part by NIH grants NS094758 to M.A.N. and AG032958 to D.G. and M.A.N.

\section{DISCLOSURE}

D. Jones reports no disclosures. E. Alvarez served on the scientific advisory boards for Teva Neuroscience, Biogen, Genzyme, Novartis, received research support from Biogen, Novartis, Acorda Alkermes. S. Selva received research support from Teva Pharmaceuticals, Rocky Mountain Multiple Sclerosis Society. D. Gilden is a senior associate editor for Journal of NeuroVirology, is on the editorial board for Journal of Virology, Neurology ${ }^{\circledR}$, Journal of the Neurological Sciences, received research support from the NIH. M.A. Nagel received research support from the NIH. Go to Neurology.org/nn for full disclosure forms.

Received March 9, 2016. Accepted in final form April 16, 2016.

\section{REFERENCES}

1. Nagel MA, Traktinskiy I, Azarkh Y, et al. Varicella zoster virus vasculopathy: analysis of virus-infected arteries. Neurology 2011;77:364-370.

2. Nagel MA, Traktinskiy I, Stenmark KR, Frid MG, Choe A, Gilden D. Varicella-zoster virus vasculopathy: immune characteristics of virus-infected arteries. Neurology 2013;80:62-68.

3. Nagel MA, Forghani B, Mahalingam R, et al. The value of detecting anti-VZV IgG antibody in CSF to diagnose VZV vasculopathy. Neurology 2007;68:1069-1073.

4. Stevens DA, Ferrington RA, Jordan GW, Merigan TC. Cellular events in zoster vesicles: relation to clinical course and immune parameters. J Infect Dis 1975;131: 509-515. 
5. Haug A, Mahalingam R, Cohrs RJ, Schmid DS, Corboy JR, Gilden D. Recurrent polymorphonuclear pleocytosis with increased red blood cells caused by varicella zoster virus infection of the central nervous system: case report and review of the literature. J Neurol Sci 2010;292: $85-88$.

6. Chomarat P, Banchereau J, Davoust J, Palucka AK. IL-6 switches the differentiation of monocytes from dendritic cells to macrophages. Nat Immunol 2000;1:510-514.

7. Nabata T, Morimoto S, Koh E, Shiraishi T, Ogihara T. Interleukin- 6 stimulates c-myc expression and proliferation of cultured vascular smooth muscle cells. Biochem Int 1990;20:445-453.

8. Sosvorova L, Kanceva R, Vcelak J, et al. The comparison of selected cerebrospinal fluid and serum cytokine levels in patients with multiple sclerosis and normal pressure hydrocephalus. Neuro Endocrinol Lett 2015;36:564-571.
9. Gilden D, White T, Khmeleva N, et al. Prevalence and distribution of VZV in temporal arteries of patients with giant cell arteritis. Neurology 2015;84:1948-1955.

10. Nadkarni S, Dalli J, Hollywood J, Mason JC, Dasgupta B, Perretti M. Investigational analysis reveals a potential role for neutrophils in giant-cell arteritis disease progression. Circ Res 2014;114:242-248.

11. Hernández-Rodríguez J, Segarra M, Vilardell C, et al. Tissue production of pro-inflammatory cytokines (IL-1beta, TNFalpha and IL-6) correlates with the intensity of the systemic inflammatory response and with corticosteroid requirements in giant-cell arteritis. Rheumatology 2004; 43:294-301.

12. Tomita T, Imakawa K. Matrix metalloproteinases and tissue inhibitors of metalloproteinases in giant cell arteritis: an immunocytochemical study. Pathology 1998;30: $40-50$. 


\title{
Neurology \\ Neuroimmunology \& Neuroinflammation
}

\author{
Proinflammatory cytokines and matrix metalloproteinases in CSF of patients with VZV \\ vasculopathy \\ Dallas Jones, Enrique Alvarez, Sean Selva, et al. \\ Neurol Neuroimmunol Neuroinflamm 2016;3; \\ DOI 10.1212/NXI.0000000000000246
}

This information is current as of June 13, 2016

$\begin{array}{ll}\begin{array}{l}\text { Updated Information \& } \\ \text { Services }\end{array} & \begin{array}{l}\text { including high resolution figures, can be found at: } \\ \text { http://nn.neurology.org/content/3/4/e246.full.html }\end{array} \\ \text { References } & \text { This article cites } 12 \text { articles, } 1 \text { of which you can access for free at: } \\ \text { http://nn.neurology.org/content/3/4/e246.full.html\#\#ref-list-1 } & \text { This article, along with others on similar topics, appears in the } \\ \text { following collection(s): } & \text { All Cerebrovascular disease/Stroke } \\ \text { http://nn.neurology.org//cgi/collection/all_cerebrovascular_disease_str } \\ \text { oke } \\ \text { Vasculitis } \\ \text { http://nn.neurology.org//cgi/collection/vasculitis } \\ \text { Viral infections } \\ \text { http://nn.neurology.org//cgi/collection/viral_infections } \\ \text { Information about reproducing this article in parts (figures,tables) or in } \\ \text { its entirety can be found online at: } \\ \text { http://nn.neurology.org/misc/about.xhtml\#permissions } \\ \text { Information about ordering reprints can be found online: } \\ \text { Permissions \& Licensing } \\ \text { http://nn.neurology.org/misc/addir.xhtml\#reprintsus }\end{array}$

Neurol Neuroimmunol Neuroinflamm is an official journal of the American Academy of Neurology.

Published since April 2014, it is an open-access, online-only, continuous publication journal. Copyright $\odot$ 2016 American Academy of Neurology. All rights reserved. Online ISSN: 2332-7812.

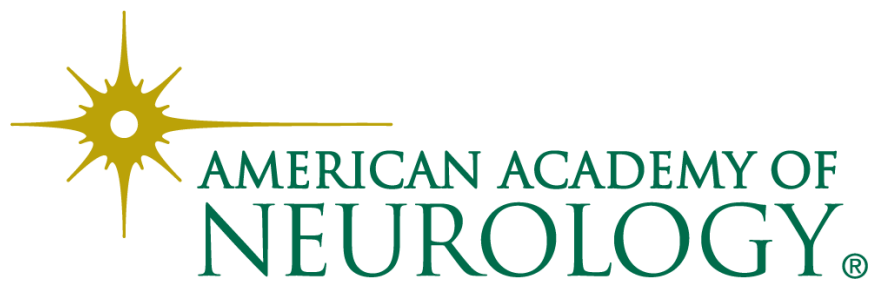

